\title{
Phylogeny and genetic relationship between hard ticks (Ixodidae) infesting cattle collected from selected areas of a wildlife-livestock interface ecosystem of Mikumi National Park, Tanzania.
}

Donath Damian ( $\nabla$ donath.damian@yahoo.com )

University of Dar es Salaam https://orcid.org/0000-0002-0500-9886

Modester Damas

University of Dar es Salaam

Jonas Johansson Wensman

Swedish University of Agricultural Sciences

Mikael Berg

Swedish University of Agricultural Sciences

\section{Research}

Keywords: Hard tick, genetic distance, phylogeny, 16S rRNA gene, Hyalomma, Rhipicephalus, Wildlifelivestock interface, Mikumi National Park

Posted Date: May 28th, 2020

DOI: https://doi.org/10.21203/rs.3.rs-30796/v1

License: (9) This work is licensed under a Creative Commons Attribution 4.0 International License.

Read Full License 


\section{Abstract \\ Background:}

There is substantial increase in the number of tick species and tick-borne infectious agents in Tanzania. Due to their impact on human, livestock and wild animal health, increased knowledge of ticks is highly needed. So far, no published data on the phylogeny and the genetic distance between hard ticks collected from cattle is available in Tanzania.

\section{Methods}

Ticks from cattle in 9 wards, which lie at the border of Mikumi National Park, were collected in dry season (November and December) 2019. Morphological identification of ticks was initially performed to genus level. To identify ticks to species level, molecular analysis based on mitochondrion 16S rRNA gene was performed. The evolutionary relationships and genetic distance between ticks were determined using Maximum Likelihood and Kimura 2-parameter methods respectively.

\section{Results}

On the basis of morphology, two genera (Rhipicephalus and Hyalomma) were identified of the 630 adult ticks collected from a total of 252 cattle. Six species; $R$. microplus, $R$. evertsi, $H$. marginatum, $H$. rufipes, $H$. truncatum and $H$. turanicum were confirmed by BLASTn and phylogenetic analysis. The considerably mean and pairwise genetic distances for Rhipicephalus and Hyalomma genera were observed, whereas, the high overall mean and pairwise genetic distances were also recorded.

\section{Conclusion}

The presence of different (clusters) phylogroups and considerably mean and pairwise genetic distances observed, reflecting possible biological diversity of hard ticks present in the study area. The outcomes of this study will be useful in the planning of integrated control strategies for ticks and tick-borne diseases in Tanzania.

\section{Background}

Ticks are obligate blood-sucking ectoparasites of mammals, birds and reptiles (1). They are responsible for severe economic losses in livestock production (2). Through blood sucking, ticks can cause reduction in livestock weight, limit livestock production and induce anemia (2). Tick bites may cause irritation which leads to secondary bacterial infections, together resulting in reduced quality of hides (2). Certain tick species inject toxin to animals, which cause paralysis when feeding blood (1). In addition, ticks are vectors of several pathogens; viruses, bacteria, protozoa and filarial nematodes, which can cause 
diseases in human, livestock and wild animals (3). Till recently, about 800 tick species are known worldwide, the most of which belong to the two main families, Ixodidae (hard ticks) and Argasidae (soft ticks) (1). Ixodidae (hard ticks) is the largest family of ticks, which are of great economic importance due to their negative social-economic impact on agriculture $(1,2,3)$. Acaricides have been the first choice in tick control for cattle farmers, but hard ticks (Ixodidae) rapidly acquire resistance to these chemicals (4). Replication slippage and recombination drive genetic diversity in tick populations $(4,5,6)$ generating point mutations and frame shifts within the genes targeted by acaricides, resulting in resistance $(4,7)$. In addition, resistance can quickly accumulate in a population due to the mating structure of ticks and their ability to produce multiple generations within one season $(5,8)$. It has, therefore, become increasingly important to clarify the level of genetic variation of hard tick population for the better development of tick control strategies.

Mikumi National Park is located in the Morogoro region of Tanzania and lies between latitudes $7^{\circ}$ and $10^{\circ}$ south of the equator and between longitudes $36^{\circ}$ and $37^{\circ}$ East of Greenwich (Fig. 1). This ecosystem is inhabited by a wide variety of wild animals and arthropods. Hence, the area is considered to be one of the epidemic foci of tick species and possibly tick-borne diseases $(9,10)$. In areas which lie at the border of Mikumi National Park, people practice nomadic pastoralism, keeping large number of indigenous cattle. Several cases of high tick infestation and tick-borne infections have been reported in livestock there in recent years $(10,11)$. Moreover, cattle trade in the country is largely unregulated, creating risks of tick and tick-borne disease dissemination that require detailed investigation. Studies on ticks prior to the present study have been conducted and three tick genera; Hyalomma, Rhipicephalus and Ambryomma were reported to be endemic $(12,13,14)$.

However, there is no phylogenic and genetic relationship (genetic distance) data for ticks of the family Ixodidae (hard ticks) infesting cattle in this area that have been published so far. Phylogeny utilizes the evidence of evolutionary relationship of species, whereas, genetic distance utilizes evidence from evolutionary divergence of species, both determine the genetic relationships of populations within species and was the main aspects of this study. The phylogenetic and genetic relationship data of Ixodidae ticks will provide valuable information to geneticists, farmers and acaricide suppliers about the differences and similarities of Ixodidae tick populations in the area. Therefore, accurate data from field studies is needed to inform rational control strategies and establish models to predict the changing epidemiology of ticks, tick-borne diseases and economic impact on livestock production.

In the present study, we analyzed the phylogeny and genetic relationship (genetic distance) of the hard tick of the genera Hyalomma and Rhipicephalus infesting cattle from the wildlife-livestock interface ecosystem of Mikumi National Park, Tanzania. Phylogeny and genetic distance of ticks were performed using the mitochondrion 16S rRNA gene. Because of the genetically high conservation and strictly maternal inheritance, the 16S rRNA gene appear to provide a reliable and convenient method for distinguish the lineage among diverse populations of hard ticks.

\section{Methods}




\section{Ticks collection}

Ticks from cattle were collected in dry season (November and December) 2019 in 26 survey points of the 9 wards which lie at the border of Mikumi National park, Morogoro region, Tanzania (Geographical coordinates $S 7^{\circ} 00 \mathrm{Q}$ to $8^{\circ} 00 \mathrm{~V}$ and $\mathrm{E} 037^{\circ} 00 \mathrm{Q}$ to $037^{\circ} 40 \mathrm{Q}$ ) (Fig. 1). Cattle were restricted and kept standing and all body parts were examined. Only adult ticks were collected by plucking using blunt forceps. Collected ticks were preserved in $70 \%$ ethanol and stored at $-20^{\circ} \mathrm{C}$ in the laboratory, at the Department of Veterinary Parasitology and Entomology, Faculty of Veterinary Medicine, Sokoine University of Agriculture, Tanzania.

\section{Identification Of Ticks To Genus Level Based On Morphology}

The morphological identification of tick genus was performed according to published taxonomic keys (1) using stereo microscopes with magnification up to 100X. This identification was conducted at the Entomology unit, Department of Parasitology and Entomology, Sokoine University of Agriculture, Tanzania.

Identification of ticks to species level based on molecular techniques

To support morphological identification, the identified ticks were confirmed by molecular analysis of the partial sequences of the mitochondrion16S rRNA gene. For each genus of tick identified morphologically, nine representative individuals were randomly selected for molecular analysis.

\section{DNA Extraction}

A total of 18 adult ticks, representatives of the 2 genera identified morphologically, were washed twice in distilled water and air dried for 15 minutes. Each individual tick was transferred into a $2 \mathrm{ml}$ micro-tube containing glass plating bead (ZymoResearch, California, USA). The tubes were frozen in liquid nitrogen for ten minutes and the ticks were ground into a powder using a Geno-grinder (SPEX Sample Prep; UK), followed by enzymatic digestion using Proteinase K (15). Genomic DNA extraction was then carried out using phenol-chloroform extraction (16). The DNA was then precipitated with absolute ethanol and resuspended in $200 \mu \mathrm{L}$ of $1 \times$ TE buffer (Tris $10 \mathrm{mM}$, EDTA $1 \mathrm{mM}$, pH8) (15).

\section{DNA Amplification}

A pair of specific primer set of 16S + 1 (5'-CTGCTCAATGATTTTTTAAATTGCTGTGG-3') and 16S-1 (5'CCGGTCTGAACTCAGATCAAGT-3') was used to target the mitochondrial 16S rRNA gene of ticks. The PCR reactions were conducted in a final volume of $20 \mu \mathrm{l}$ containing $10 \mu \mathrm{l}$ of PCR NEB One Taq 2X Master Mix 
with Standard Buffer, $6 \mu \mathrm{l}$ of nuclease free water, $1 \mu \mathrm{l}$ of $10 \mu \mathrm{mol} / \mathrm{L}$ of each primer and $2 \mu \mathrm{l}$ of DNA template (15). The PCR was carried out using a Thermo Scientific Arktik Thermal Cycler (TC A0096). The protocol for the $16 \mathrm{~S}$ rRNA gene amplification using $16 \mathrm{~S}+1 / 16 \mathrm{~S}-1$ was: initial denaturation $95^{\circ} \mathrm{C}$ for $5 \mathrm{~min}$; followed by 10 cycles of $92^{\circ} \mathrm{C}$ for $1 \mathrm{~min}, 48^{\circ} \mathrm{C}$ for $1 \mathrm{~min}$ and $72{ }^{\circ} \mathrm{C}$ for $1.5 \mathrm{~min} ; 32$ cycles of $92^{\circ} \mathrm{C}$ for $1 \mathrm{~min}, 54^{\circ} \mathrm{C}$ for 35 seconds, $72^{\circ} \mathrm{C}$ for $1.5 \mathrm{~min}$, followed by final extension of $72{ }^{\circ} \mathrm{C}$ for 7 min (460 bp) (15). For each PCR reaction, a negative control containing deionized distilled water was included.

\section{Agarose Gel Analysis And Purification Of Amplicons}

PCR products were visualized in $1.4 \%$ agarose gel (CSL-AG500, Cleaver Scientific Ltd) stained with EZvision ${ }^{\circledR}$ Blue light DNA Dye in Tris-Acetate-EDTA (TAE Buffer) under UV light after staining with Gel Red Nucleic Acid Stain(https://biotium.com/product/gelred-nucleic-acid-gel-stain/). A100bp DNA ladder was used as a standard marker. The amplicons were purified using QIAquick PCR Purification Kit (Qiagen, Hilden, Germany) according to manufacturer's protocol. The concentrations of purified PCR products were determined using a spectrophotometer.

\section{Sequencing Of The 16s rRNA Amplicons}

Fragments were sequenced at Inqaba South Africa using the same forward and reverse primers as used to generate the PCR products. The labeled products were then cleaned with the ZR-96 DNA Sequencing Clean-up Kit (http://www.zymoresearch). The cleaned products were injected on the Applied Biosystems ABI 3500XL Genetic Analyzer with a $50 \mathrm{~cm}$ array using POP7 (https://www.thermofisher.com). Sequence chromatogram analysis was performed using Finch TV analysis software (https://www.softpedia.com/get/Science-CAD/FinchTV.shtml).

\section{Sequences Editing And Identity Confirmation}

Sequences were edited using BioEdit in MEGA X software (17). To confirm the identity of each tick species, the sequences were compared with those available in the GenBank database using the BLASTn program (https://blast.ncbi.nIm.nih.gov/Blast.cgi). For the BLASTn algorithm, a stringent E-value cut-off $\left(10^{-6}\right)$ was used as described previously (13). The identity of the query sequence was assigned to the best hit (highest bit score) returned from BLASTn. The query ID was regarded as confirmed when the best hit (highest bit score) had an E-value below $10^{-6}$ (18).

\section{Sequences Alignment}

Representative mitochondrion 16S rRNA gene sequences of Rhipicephalus microplus, $R$. evertsi, Hyalomma rufipes, $H$. marginatum, $H$. truncatum and $H$. turanicum were downloaded from GenBank. Downloaded sequences and sequences generated in the present study were aligned by multiple sequence 
alignment using MUSCLE in MEGAX software $(17,19)$. The sequences acquired in this study have been deposited in the GenBank database with accession numbers MT0798663 to MT079880.

\section{Phylogenetic Analysis}

To determine the genetic relationship between different tick species and to infer their evolutionary history, a phylogenetic tree was constructed. To build the tree, reference sequences of the mitochondrion $16 \mathrm{~S}$ rRNA gene downloaded from GenBank database were aligned along with the sequences generated in the present study. The evolutionary history was inferred by using the Maximum Likelihood (ML) method with 100 replications in the bootstrap test and Tamura 3-parameter mode (17). Initial tree for the heuristic search was obtained automatically by applying Neighbor-Joining and BioNJ algorithms to a matrix of pairwise distances estimated using the Maximum Composite Likelihood (MCL) approach, and then selecting the topology with superior log likelihood value (17). The tree was drawn to scale, with branch lengths measured in the number of substitutions per site. This analysis involved 24 nucleotide sequences, 18 generated from the present study and the rest from GenBank. Evolutionary analyses were conducted in MEGA X software (19).

\section{Evolutionary divergence (genetic distance) of ticks}

To further determine the evolutionary divergence of the ticks collected in this wildlife-livestock interface ecosystem, mean and pairwise genetic distance analysis were conducted using Kimura's 2-parameter (K2P) model (20). The analysis involved the sequences generated in the present study only. Standard error estimates were obtained by a bootstrap procedure (100 replicates). All ambiguous positions were removed for each sequence pair (pairwise sequence deletion option) (20). The mean and pairwise genetic distance analysis was conducted in MEGAX software (19).

\section{Results}

\section{Ticks collection and identification}


Table 1

Number of ticks collected from cattle in selected areas of the wildlife-livestock interface ecosystem of Mikumi National Park, Tanzania.

\begin{tabular}{|lllll|}
\hline Ward & $\begin{array}{l}\text { Number of cattle infested with } \\
\text { ticks }\end{array}$ & $\begin{array}{l}\text { Number of ticks } \\
\text { collected }\end{array}$ & Rhipicephalus & Hyalomma \\
\hline Mikumi & 32 & 76 & 62 & 14 \\
\hline Doma & 44 & 112 & 82 & 30 \\
\hline Kidodi & 30 & 69 & 30 & 39 \\
\hline Ulaya & 28 & 63 & 32 & 31 \\
\hline Melela & 36 & 102 & 48 & 54 \\
\hline Kisaki & 38 & 106 & 64 & 42 \\
\hline Kilangili & 14 & 35 & 22 & 13 \\
\hline Ruhembe & 20 & 37 & 18 & 19 \\
\hline Tindiga & 10 & 30 & 13 & 17 \\
\hline Total & 252 & 630 & 371 & 259 \\
\hline
\end{tabular}

A total of 630 adult ticks were collected from 252 cattle in 9 wards, which lie at the border of Mikumi National Park, Tanzania (Table 1). On the basis of morphology, all ticks were classified into two genera; Rhipicephalus (371) and Hyalomma (259) (Table 1). Due to morphological similarity among ticks, all specimens were identified to genus level. Specimens of Rhipicephalus and Hyalomma genera were grouped by similarity and 9 representative individuals from each group were randomly selected. To confirm results of morphological identification, partial mitochondrion 16S rRNA gene was used as a molecular marker in species identification. A total of 18 specimens were sequenced, edited, aligned and the BLASTn analysis was performed. The lengths of the aligned sequences varied from 399 to 453 base pairs and the nucleotide components indicate that mitochondrion16S rRNA gene of these ticks is highly A-T rich with average nucleotide frequencies of Thymine (36.77\%), Cytosine (9.51\%), Adenine $(39.71 \%)$ and Guanine (13.99\%). A bias toward Adenine and Thymine (76.48\%) was consistent with the base composition of arthropod mitochondrial DNA. The results from molecular identification are summarized in Table 2. BLASTn matched morphological results with identity varying between 92 and 100\% (Table 2). Molecular results revealed that, among the specimens of the genus Rhipicephalus, five were $R$. microplus and one was $R$. evertsi, whereas, for Hyalomma genus, five were identified as $H$. marginatum, three were $H$. truncatum, two as $H$. rufipes and two as $H$. turanicam. $R$. microplus and $H$. marginatum out numbered all other tick species and together they represent $56 \%$ of the total ticks sequenced in the present study (Table 2). 
Table 2

Sampled tick species and percentage identity value with the references sequences

\begin{tabular}{|c|c|c|c|c|c|}
\hline $\begin{array}{l}\text { Sample } \\
\text { accessions } \\
\text { numbers }\end{array}$ & $\begin{array}{l}\text { Sample } \\
\text { collection } \\
\text { ward }\end{array}$ & $\begin{array}{l}\text { GenBank } \\
\text { accession } \\
\text { numbers }\end{array}$ & $\begin{array}{l}\text { Percentage } \\
\text { Identity }\end{array}$ & Tick species & $\begin{array}{l}\text { Source } \\
\text { country }\end{array}$ \\
\hline МT079863 & Mikumi & EU918187 & 99.50 & R. microplus & Mozambique \\
\hline МT079864 & Mikumi & MK737650 & 98.76 & H. rufipes & Egypt \\
\hline MT079865 & Doma & KC170742 & 100 & $\begin{array}{l}R . \\
\text { micropmus }\end{array}$ & Thailand \\
\hline МT079866 & Doma & KU130478 & 97.15 & H.truncatum & South Africa \\
\hline МT079867 & Kidodi & KP776645 & 98.99 & $\begin{array}{l}\mathrm{H} \text {. } \\
\text { marginatum }\end{array}$ & France \\
\hline МT079868 & Kidodi & KT391063 & 94.24 & H.turanicum & Israel \\
\hline МT079869 & Ulaya & KP776654 & 94.70 & $\begin{array}{l}H . \\
\text { marginatum }\end{array}$ & France \\
\hline MT079870 & Ulaya & EU918187 & 99.75 & R. microplus & Mozambique \\
\hline MT079871 & Melela & L34307 & 97.72 & $\begin{array}{l}H . \\
\text { marginatum }\end{array}$ & USA \\
\hline MT079872 & Melela & KU130478 & 96.89 & $\begin{array}{l}\mathrm{H} \text {. } \\
\text { truncatum }\end{array}$ & South Afica \\
\hline MT079873 & Kisaki & KC170742 & 99.26 & R. microplus & Thailand \\
\hline MT079874 & Kisaki & KU130465 & 99.49 & H. rufipes & South Africa \\
\hline MT079875 & Kilangili & KJ613642 & 98.42 & R. evertsi & South Africa \\
\hline MT079876 & Kilangili & EU918187 & 99.50 & R. microplus & Mozambique \\
\hline MT079877 & Ruhembe & KT391063 & 91.54 & $\begin{array}{l}\text { H. } \\
\text { turanicum }\end{array}$ & Israel \\
\hline МT079878 & Ruhembe & KP776645 & 98.50 & $\begin{array}{l}H . \\
\text { marginatum }\end{array}$ & France \\
\hline MT079879 & Tindiga & KU130478 & 96.37 & $\begin{array}{l}\text { H. } \\
\text { truncatum }\end{array}$ & South Africa \\
\hline МT079880 & Tindiga & KP776645 & 97.47 & $\begin{array}{l}H . \\
\text { marginatum }\end{array}$ & France \\
\hline
\end{tabular}

\section{Phylogenetic Analysis Of The Mitochondrion16s rRNA Gene}


Eighteen sequences representing the two identified tick genera generated in the present study and six reference sequences downloaded from GenBank database were used to infer phylogenetic relationship of tick species. To determine the evolutionary relationship of species, sequences from each species generated in the present study were aligned along with the representative sequences downloaded from the GenBank. The Maximum Likelihood tree from mitochondrion 16S rRNA gene sequences derived from Rhipicephallinae and Hyalomminae sub-families generated five (clusters) phylogroups (A, B, C, D and E) (Fig. 2). Group A, constitutes Rhipicephalus genus with two monophyletic groups; $R$. microplus and $R$. evertsi. Group B, was members of $H$. truncatum, group $C$ comprises $H$. rufipes, group $D$ comprises members of $H$. turanicum and group E comprises $H$. marginatum members (Fig. 2). There was strong bootstrap support among the species of Rhipicephalus microplus, R. evertsi, Hyalomma truncatum and H. turancum (Fig. 2). The results provided weak support in bootstrap analysis for the clusters containing Hyalomma rufipes and $H$. marginatum (Fig. 2). The high bootstrap value (100\%) supported the close relationship between Rhipicephalus microplus and R. evertsi (Fig. 2).

\section{Evolutionary divergence (genetic distance) of ticks}

\section{Due to technical limitations, Table 3 is provided in the Supplementary Files section.}

Using K2P model, sample divergences at various taxonomic levels are shown in Tables 3 and 4. To determine the evolutionary divergence (distance) within the species, sequences from each species generated in the present study were aligned and the K2P distance model was then used to determine the mean and pairwise distances. $H$. marginatum recorded the highest mean intraspecies distance value, whereas, $R$. microplus recorded the lowest (Tables 3 and 4 ). The highest pairwise intraspecies value was recorded in $H$. marginatum and the lowest pairwise intraspecies values were observed in $R$. microplus and H. truncatum (Tables 3 and 4). Likewise, 16S rRNA gene sequences from each genus generated in the present study were aligned to determine the evolutionary distance of tick within the genus. The K2P distance model was thereafter applied to infer the mean and pairwise distances. The highest pairwise intragenus value was recorded in Hyalomma genus, whereas, the lowest pairwise intragenus value was recorded in Rhipicephalus genus (Table 4). Notably, the mean evolutionary divergences were recorded to be considerably high in both genera (Table 4). Finally, to determine the overall genetic distance of the overall tick community, all 16S rRNA sequences generated in the present study were aligned and the K2P model used to estimate genetic distance. The overall high mean distance of $0.11 \pm 0.01$ (Table 4) and the high pairwise maximum distance value of 0.23 were recorded in the present study (Table 3 ). 
Table 4

The mean, maximum and minimum evolutionary divergence

\begin{tabular}{|llll|}
\hline & Mean distance & \multicolumn{2}{l|}{ Pairwise distance } \\
\hline Species & values & Minimum & Maximum \\
\hline Rhipicephalus microplus & $0.01 \pm 0.00$ & 0.003 & 0.02 \\
\hline Hyalomma marginatum & $0.04 \pm 0.01$ & 0.015 & 0.06 \\
\hline Hyalomma truncatum & $0.01 \pm 0.00$ & 0.003 & 0.015 \\
\hline Hyalomma rufipes & $0.02 \pm 0.00$ & 0.02 & 0.02 \\
\hline Hyalomma turanicum & $0.03 \pm 0.00$ & 0.03 & 0.03 \\
\hline Genus & & & \\
\hline Rhipicephalus & $0.04 \pm 0.01$ & 0.003 & 0.099 \\
\hline Hyalomma & $0.06 \pm 0.01$ & 0.003 & 0.139 \\
\hline Overall tick community & & & \\
\hline Tick community & $0.11 \pm 0.01$ & 0.003 & 0.234 \\
\hline
\end{tabular}

\section{Discussion}

In the present study, we analyzed the phylogenetic relationship and genetic distance of the hard ticks (Ixodidae) infesting cattle using the mitochondrion 16S rRNA gene. The phylogenetic and genetic relationship data will provide valuable information to geneticists, farmers and acaricide suppliers about the differences and similarities of Ixodidae tick populations in the area and could also be useful in the planning of integrated control strategies for ticks and tick-borne diseases in Tanzania.

As shown in the results, the Maximum Likelihood tree generated in the present study recorded several clusters (groups) of the mitochondrion 16S rRNA gene sequences, indicating high divergence of the gene sequences of hard ticks $(21,22,23)$ present in this wildlife-livestock interface ecosystem. In that way, clusters of similar sequences represent species clearly separated from other clusters (species) $(24,25$, $26)$. Therefore, this is a reflection of high biological diversity of ticks within Ixodidae (hard ticks) $(27,28$, 29) present in this wildlife-livestock interface ecosystem.

From the intraspecies genetic distance data generated in the present study; Hyalomma marginatum, $\mathrm{H}$. rufipes and $H$. turanicum recorded considerably high mean and pairwise intraspecies genetic distances. On the other hand, Rhipicephalus microplus and Hyalomma truncatum recorded low mean and pairwise intraspecies genetic distances. The considerably high genetic distances recorded in $H$. marginatum, $H$. rufipes and $H$. turanicum suggest that different groups of these species might represent distinct species or subspecies, or that the species are species complexes with high genetic diversity (30). The low value of 
divergence recorded in $R$. microplus and $H$. truncatum might indicate hybridization (30) or misidentification among the species $(31,32)$.

From the intragenus genetic distance data generated here, Hyalomma spp., recorded considerably high mean and pairwise genetic distance. The considerably high mean and pairwise genetic distances recorded in Hyalomma genus suggest high biological diversity in this group (genus) of hard ticks $(29,32)$. Therefore, either new species or subspecies closely related to those recorded in the present study might exist or that these ticks form species complexes with divergent lineages in this wildlife-livestock interface ecosystem (32). The interbreeding between Hyalomma rufipes, $H$. marginatum and $H$. turanicum populations has already been demonstrated $(33,34)$ and these hybrid forms can be transported to different regions by migratory birds $(34,35,36,37,38)$. Therefore, it is possible to find hybrid forms as a result from the interbreeding of two or three species in regions where these species are found $(37,38)$. This could explain for the wide sequence variability (divergences) for Hyalomma spp., particularly for Hyalomma marginatum. H. turanicum and $H$. rufipes $(34,38)$ as observed in the current study.

The mean and pairwise genetic distances in the overall tick community recorded in the present study were highly similar to other studies $(32,33)$. Such considerably genetic distance values reflect the high biological diversity within the hard tick community present in this wildlife-livestock interface ecosystem (32).

As expected, the mean genetic distances recorded in the present study increased with higher taxonomic ranking; $0.01 \pm 0.00,0.06 \pm 0.01$ and $0.11 \pm 0.01$ for intraspecies, intragenus and overall tick community respectively. This makes the mitochondrion 16S rRNA gene to be a good marker for supraspecific differentiation and mainly, for taxa grouping purposes $(28,29,39)$. According to Ros et al. (2007) (40), DNA barcoding assumes that the genetic distances between species are greater than within species.

\section{Conclusion}

The presence of different (clusters) phylogroups and considerable genetic distances observed, reflect the possible biological diversity of hard ticks present in the study area. Therefore, further work is required to delineate species boundaries and to develop a more complete understanding of hard tick diversity over larger scale.

\section{Abbreviations}

BLAST: Basic Local Alignment Search Tool, H: Hyalomma, K2P: Kimura's 2-parameter, R: Rhipicephalus, ML: Maximum Likelihood, MCL: Maximum Composite Likelihood, NJ: Neighbor-Joining, MEGA: Molecular Evolution Genetic Analysis.

\section{Declarations}


In particular, we thank the Swedish Government and Swedish International Development Cooperation Agency (SIDA) for contributions and financial support. We also extend special thanks to the University of Dar es Salaam, Tanzania, and Swedish University of Agricultural Sciences, Sweden for supporting this research work, as well as our colleagues and researchers at the Swedish University of Agricultural Sciences Global Bioinformatics Centre who provided valuable knowledge and skills concerning Bioinformatics. We thank the livestock keepers, village and ward leaders from each location for their help with ticks collection, as well as entomologists from Sokoine University of Agriculture who assisted in tick morphological identification.

\section{Funding}

This work was funded by the Swedish Government through the Swedish International Development Agency (SIDA) in collaboration with the University of Dar es Salaam and the Swedish University of Agricultural Sciences.

\section{Availability of data and materials}

The data supporting the conclusions of this article are included within the article. The sequences generated in the present study were submitted to GenBank under the accession numbers MT079863 to MT079880

\section{Author's contributions}

DD designed the investigation, performed the experiments, conducted the investigation and drafted the manuscript. MD designed the investigation, conceived the study and revised the manuscript. JJW and MB conceived the study, designed the investigation and revised the manuscript. All authors read and approved the final manuscript.

\section{Ethics approval and consent to participate}

No specific permits were required for this study. The study did not involve endangered or protected species. Therefore, the local ethics committee deemed that approval was unnecessary.

\section{Consent to publication}

Not applicable.

\section{Competing Interests}

The authors declare that they have no competing interests

\section{Publishers Note}

Springer Nature remains neutral with regards to jurisdictional claims in published maps and institutional affiliations. 


\section{Author details}

\section{Donath Damian}

Mr. Damian received a Bachelor degree in Molecular Biology and Biotechnology from the University of Dar es Salaam, Tanzania and a Master of Science in Biochemistry from Muhimbili University of Health and Allied Sciences, Tanzania. He is currently a PhD student in Molecular Biosciences at the University of Dares Salaam Department of Molecular Biology and Biotechnology.

Email address donath.damian@yahoo.com, Box 35091 Dar es Salaam, Tanzania (corresponding Author).

\section{Modester Damas}

Dr. Damas received a Bachelor degree in Molecular Biology and Biotechnology and a Master's of Science in Molecular Biology from the University of Dar es Salaam. She obtained her PhD in Virology at Hannover Medical School in Hannover, Germany.

\section{Jonas Johansson Wensman}

Dr. Wensman received his Master of Science in Veterinary Medicine and his PhD in Virology from the Swedish University of Agricultural Sciences, Sweden. He is currently an Associate Professor in the Section of Ruminant Medicine, Department of Clinical Sciences at the Swedish University of Agricultural Sciences in Uppsala, Sweden.

\section{Mikael Berg}

Prof. Berg received a Bachelor degree in Microbiology from Uppsala University, Sweden. He specialized in veterinary virology and obtained his PhD from the Swedish University of Agricultural Sciences. He is currently a Professor of Veterinary Virology in the Department of Biomedical Sciences and Veterinary Public Health at the Swedish University of Agricultural Sciences, Sweden.

\section{References}

1. Walker AR, Bouattour A, Camicas JL, Estrada-Pena A, Horak IG, Latif AA, et al. Ticks of domestic animals in Africa: a guide to identification of species. Edinburgh: Bioscience Reports.

2. Jongejan F and Uilenberg G. The global importance of ticks. Parasitology. 2004; 129: 3-14.

3. Estrada-Peña A, Gray JS, Kahl O, Lane RS and Nijhof AM. Research on the ecology of ticks and tickborne pathogens, methodological principles and caveats. Frontiers in Cellular and Infection Microbiology. 2013; 3:29.

4. Baffi MA, De Souza GR and Vieira CU. Identification of point mutations in putative carboxylestarase and their association with acaricide resistance in Rhipicephalus(Boophilus) microplus. Vet Parasitol. 2007; 148: 301-309. 
5. Li AY, Chen AC, Miller RJ, Davey RB and George JE. Acaricides resistance and synergisms between permethrin and amatraz against susceptible and resistant strains of Boophilusmicroplus (Acari:Ixodidae). Pest Manag Sci. 2007; 63:882-889.

6. Chevillon C, Ducornez S, Koffi B and Gai H. Accumulation of Acaricide resistance mechanisms in Rhipicephalus (Boophilus) microplus (Acari: Ixodidae) populations from New Caledonia Island. Vet Parasitol. 2007; 147:276-288.

7. Hernandez R, Guerro FD, George JE and Wagner G. Allele frequency and gene expression of a putative carboxylesterase-encoding gene in a pyrethroid resistance strain of tick Boophilus microplus. Insect BiochemMolec. 2002; 32:1009-1016

8. Cutulle $\mathrm{C}$, Jonsson N and Seddon J. Population structure of Australian Isolates of cattle tick Rhipicephalus (Boophilus) microplus. Vet Parasitol. 2009; 161: 283-291.

9. Kambarage DM. East Coast fever as a continued constraint to livestock improvement in Tanzania: a case study. Trop Anim Health Prod. 1995; 27: 145-149.

10. Ogden NH, Swai E, Beauchamp G, Karimuribo E, Fitzpatrick JL, Bryant MJ, Kambarage D and French NP. Risk factors for tick attachment to small holder dairy cattle in Tanzania. Prev Vet Med.2005; 67: 157-170.

11. Laisser ELK, Kipanyula MJ, Msalya G, Mdegela RH, Karimuribo ED, Mwilawa AJ, Mwega ED, Kusiluka LJM and Chenyambuga SW. Tick burden and prevalence of Theileriaparva infection in Tarime zebu cattle in the Lake zone of Tanzania. Anim. Health Prod. 2014; 46:1391-1396.

12. Lynen G, Zeman P, Bakuname C, Di Giulio G, Mtui P, Sanka P and Jongejan F. Cattle ticks of the genera Rhipicephalus and Amblyomma of economic importance in Tanzania: distribution assessed with GIS based on an extensive field survey. Appl. Acarol. 2007; 43: 303-319.

13. KwakYS, Kim TY, Man SH, Lee IY, Kim HP, Mduma S, Keyyu J, Fyumagwa R and Yong TS. Ixodid tick infestation in cattle and wild animals in Maswa and Iringa, Tanzania. Korean J. Parasitol. 2014; 5:565-568.

14. Kerario I, Muleya W, Chenyambuga S, Koski M, Hwang S and Simuunza M. Abundance and distribution of Ixodid tick species infesting cattle reared under traditional farming systems in Tanzania. African journal of agricultural sciences.2017; 12: 286-299.

15. Hill C.A. Gutierrez J.A. Method for extraction and analysis of high quality genomic DNA from ixodid ticks, Vet. Entomol.2003; 12: 224-227.

16. Wallace DM. Large and small scale phenol extractions Guide to Molecular cloning techniques. Academic Press, Orlandopp.1987; 152: 33-41.

17. Tamura K, Peterson D, Peterson N, Stecher G, Nei M and Kumar S. MEGA5: Molecular evolutionary genetics analysis using maximum likelihood, evolutionary distance, and maximum parsimony methods. Biol. Evol. 2011; 28: 2731-2739.

18. Ross HA, Murugan S and Li WL. Testing the reliability of genetic methods of species identification via Syst Biol. 2008; 57:216-30. 
19. Kumar S, Stecher G, Li M, Knyaz C and Tamura K. MEGA X: Molecular Evolutionary Genetics Analysis across computing platforms. Molecular Biology and Evolution.2018; 35:1547-1549.

20. Kimura M.A simple method for estimating evolutionary rate of base substitutions through comparative studies of nucleotide sequences. Mol. Evol. 1980; 16:111-120.

21. Bursali A, Keskin A andTekin S. A review of the ticks (Acari: Ixodida) of Turkey: species diversity, hosts and geographical distribution. Appl. Acarol. 2012; 57: 91-104.

22. Barker S and Murrell A. Phylogeny, evolution and historical zoogeography of ticks: a review of recent progress. Appl. Acarol. 2002; 28:55-68.

23. Low V, Tay S, Kho K, Koh F, Tan T, Lim Y, Ong B, Panchadcharam C, Rashid Y and Sofian-Azirun M. Molecular characterisation of the tick Rhipicephalus microplus in Malaysia: new insights into the cryptic diversity and distinct genetic assemblages throughout the world. Parasites \& Vectors. 2015; 8:341.

24. Black WC and Piesman J. Phylogeny of hard- and soft-tick taxa (Acari: Ixodida) based on mitochondrial 16S rRNA sequences. ProcNatIAcadSci USA.1994; 91: 10034-10038.

25. Taberlet $P$, Meyer A and Bouvet J. Unusual mitochondrial DNA polymorphism in two local population of blue tit (Paruscaeruleus).Molecular Ecology Resources. 1997; 1:27-36.

26. Rees DJ, Dioli M and Kirkendall LR. Molecules and morphology: evidence for cryptic hybridization in African Hyalomma (Acari: Ixodidae). 2003; 27: 131-142.

27. Burger TD, Shao R and Barker SC. Phylogenetic analysis of mitochondrial genome sequences indicates that the cattle tick, Rhipicephalus(Boophilus) microplus, contains a cryptic species. 2014;76:241-53.

28. Kaur H, ChhilarJS, Chhillar S. Mitochondrial 16S rRNA based analysis of some hard ticks belonging to genus HyalommaKoch, 1844 (Acari: Ixodidae). J AdvParasitol. 2016; 3: 32-48.

29. Lv J, Wu S, Zhang Y, Chen Y, Feng C, Yuan X, et al. Assessment of four DNAfragments (COI, 16S rRNA, ITS2, 12S rDNA) for species identification of thelxodida (Acari: Ixodida). Parasit Vectors.2014; 7: 93.

30. Waugh J. DNA barcoding in animal species: progress, potentialand pitfalls. 2007; 29: 188-197.

31. Sheth BP and Thaker VS. DNA barcoding and traditional taxonomy: an integrated approach for biodiversity conservation. 1997; 60: 618-628.

32. Lu X, Lin XD, Wang JB, Qin XC, Tian JH, Guo WP. Molecular survey of hard ticks in endemic areas of tick-borne diseases in China. Ticks \&Tick Borne Dis.2013; 4: 288-96.

33. Apanaskevich DA and Horak IG.The genus Hyalomma Koch, 1844: V. Re-evaluation of the taxonomic rank of taxa comprising the (Euhyalomma) marginatum Koch complex of species (Acari: Ixodidae) with redescription of all parasitic stages and notes on biology. Int J Acarol. 2008; 34:13-42.

34. Estrada-Peña A, Sánchez, N, Estrada-Sánchez A. An assessment of the distribution and spread of the tick Hyalomma marginatum in the western Palearctic under different climate scenarios. Vector-Borne Zoonotic Dis. 2012; 12: 758-768 
35. Kaiser MN, Hoogstraal H, Watson GE. Ticks (Ixodoidea) on migrating birds in Cyprus, fall 1967 and spring 1968, and epidemiological considerations. Entomol. Res.1974; 34: 97-110

36. Hasle G, Bjune G, Edvardsen E, Jakobsen C, Linnehol B, Roer JE, Mehl R, RoedKH, Pedersen J, Leinaas HP. Transport of ticks by migratory passerine birds to Norway. Parasitol. 2009;95:13421351

37. Mancini F, Toma L, Ciervo A, Di Luca M, Faggioni G, Lista F, Rezza G. Virus investigation in ticks from migratory birds in Italy. New Microbiologica. 2013; 36:433-434.

38. Hoogstraal H, Kaiser MN, Traylor MA, Guindy E, Gaber S. Ticks (Ixodidae) on birds migrating from Europe and Asia to Africa, 1959-61. Bull World Health Organ.1961; 24:197-212.

39. Hekimoglu $O$ and Ozer AN. Distribution and phylogeny of Hyalomma ticks (Acari: Ixodidae) in Turkey. Appl. Acarol. 2017; 73: 501-519.

40. Ros VI and Breeuwer JA. Spider mite (Acari:Tetranychidae) mitochondrial $\mathrm{CO} 1$ phylogeny reviewed: host plant relationships, phylogeography, reproductive parasites and barcoding. Appl. Acarol. 2007; 42: 239-262.

\section{Supplementary Files}

This is a list of supplementary files associated with this preprint. Click to download.

- GraphicalAbstractlmage.jpg

- Table3.docx 